\title{
VINCENT BIERCE, La charité à l'épreuve du roman balzacien
}

\section{Marco Stupazzoni}

\section{OpenEdition}

\section{Journals}

\section{Edizione digitale}

URL: https://journals.openedition.org/studifrancesi/31953

DOI: 10.4000/studifrancesi.31953

ISSN: 2421-5856

\section{Editore}

Rosenberg \& Sellier

\section{Edizione cartacea}

Data di pubblicazione: 1 août 2020

Paginazione: 422

ISSN: 0039-2944

\section{Notizia bibliografica digitale}

Marco Stupazzoni, «VINCENT BIERCE, La charité à l'épreuve du roman balzacien», Studi Francesi [Online], 191 (LXIV | II) | 2020, online dal 01 septembre 2020, consultato il 18 septembre 2021. URL: http:// journals.openedition.org/studifrancesi/31953 ; DOI: https://doi.org/10.4000/studifrancesi.31953

Questo documento è stato generato automaticamente il 18 septembre 2021.

\section{(9) $\odot \Theta \Theta$}

Studi Francesi è distribuita con Licenza Creative Commons Attribuzione - Non commerciale - Non opere derivate 4.0 Internazionale. 


\title{
VINCENT BIERCE, La charité à l'épreuve du roman balzacien
}

\author{
Marco Stupazzoni
}

\section{NOTIZIA}

VINCENT BIERCE, La charité à l'épreuve du roman balzacien, "Romantisme" 180, 2018, pp. 33-45.

1 Opposta alla inefficacia della filantropia, a cui Balzac rimprovera di non fondarsi su principi religiosi ma soltanto sull'amour-propre, la carità è, al contrario, rappresentata, nella Comédie humaine, come una pratica nuova e funzionale in relazione al ruolo da essa assunto nella società contemporanea. Ne L'Envers de l'histoire contemporaine (1846), l'organizzazione e l'applicazione dei principi di carità cristiana sono affidate all'associazione dei Frères de la Consolation fondata da Mme de la Chanterie: vera e propria società occulta (speculare e inversa all'associazione criminale dei Treize), essa esercita la sua influenza tra le pieghe della società moderna ormai piegata alle leggi del capitalismo. L'Envers, osserva l'A., «donne ainsi à lire la représentation d'une bienfaisance dont l'efficacité se fonde sur une dialectique subtile» e su una critica della società «par le biais d'une autre conception, utopique, de la réalité» (p. 39).

2 In altri romanzi della Comédie humaine, quali Le Médecin de campagne (1833) e Le Curé de village (1841), è presente un'idea di carità che risulta efficace soltanto se legata all'interesse personale di personaggi laici. In entrambe le opere, Balzac propone una «solution sociale» a forte valenza utopica che rimette in discussione il concetto stesso di una carità legato a soluzioni religiose considerate ormai obsolete. In altri termini, «par l'utopie, Gérard et Benassis agissent en effet directement au niveau de la production, et l'utopie est plus efficace que la charité classique parce qu'elle est plus créative» (p. 44). 